\section{EMBRYARIDDLE}

Aeronautical University

SCHOLARLY COMMONS
Journal of Aviation/Aerospace

Education \& Research

Volume 1

Number 3 JAAER Spring 1991

Article 1

Spring 1991

\title{
A Study of Flap Management, an Analysis of the Consequences of Flap Management, and a Search for Possible Causes
}

Norbert R. Kluga

Follow this and additional works at: https://commons.erau.edu/jaaer

\section{Scholarly Commons Citation}

Kluga, N. R. (1991). A Study of Flap Management, an Analysis of the Consequences of Flap Management, and a Search for Possible Causes. Journal of Aviation/Aerospace Education \& Research, 1(3).

https://doi.org/10.15394/jaaer.1991.1026

This Article is brought to you for free and open access by the Journals at Scholarly Commons. It has been accepted for inclusion in Journal of Aviation/Aerospace Education \& Research by an authorized administrator of Scholarly Commons. For more information, please contact commons@erau.edu. 


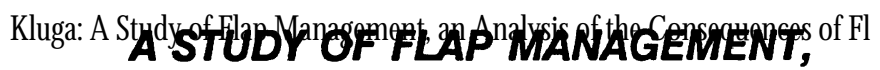 \\ AN ANALYSIS OF THE CONSEQUENCES OF FLAP MISMANAGEMENT, AND A SEARCH FOR POSSIBLE CAUSES
}

\author{
Norbert R. Kluga
}

\begin{abstract}
An exploration of current aviation education as to the purpose, aerodynamic theory, and proper usage of high lift devices, particularly trailing-edge wing flaps, was conducted. Aircraft accident data involving the mismanagement of the wing flaps as a cause/factor were analyzed and typical accidents were studied. The accident data show that a relatively high number of flap-related accidents occur and with dangerous consequences. Flight tests were conducted to recreate certain conditions of flight reported in the accident data. The following paper presents an in-depth explanation of the purpose, the aerodynamic theory, and the aircraft performance related to the proper usage of wing flaps. Additional data relative to the dangers of flight safety associated with the incorrect use of wing flaps is included. This study was primarily concerned with single-engine and twin-engine airplanes used for flight training.
\end{abstract}

\section{INTRODUCTION}

During the preparation of lectures for a course in basic aerodynamics, a number of aviation textbooks and flight manuals were studied for material concerning the management of wing flaps. It was observed that there is no consistency in how the various aspects of wing flaps are explained. In some flight training manuals and textbooks, there are statements of the purpose of flaps and descriptions of the different types of flaps available, while in other textbooks there are explanations of the changes in the coefficients of lift and drag caused by the extension and retraction of wing flaps.

In pilot operating handbooks, instructions for the use of flaps are brief statements of what amount of flaps to use for takeoffs and landings. However, these handbooks generally do not explain the reasons for a particular flap setting or restriction. As a consequence, an investigation was begun of the purpose of wing flaps, the aerodynamic theory of wing flaps, the procedures for the use of wing flaps, and the reports of flap-related accidents.
A review of the National Transportation Safety Board (NTSB) Briefs of Accidents for a six-year period showed that, on an average, one flap-related accident occurred every 9.4 days, injuring three persons, one, fatally. To investigate more the mismanagement of flaps, specifically during a go-around, flight tests were conducted duplicating certain accident conditions.

\section{METHOD}

A review of related literature was conducted for material concerning: (a) aerodynamics theory related to wing flaps; (b) the purpose of high lift devices, particularly trailing edge wing flaps; (c) types of high lift devices; (d) the procedures for the use of wing flaps; and (e) flap management and the dangers of mismanagement.

The NTSB Briefs of Accidents were analyzed to determine: (a) the types of flight operations involved and the number of accidents which occurred during each of these phases of flight, (b) the number of accidents that were training related, and (c) the number of types and injuries involved. In addition, each category of 
accidents was analyzednal and the aspespactiof fylation mismanagement involved was discussed.

Aircraft performance data for a generic, single-engine airplane in the clean and flaps-down configurations were computergenerated to show the impact of wing flaps on aircraft performance. In addition, flight tests were conducted in a Cessna $172 \mathrm{~N}$ to document go-around performance at different flap settings.

\section{REVIEW OF RELATED LITERATURE}

A review of literature related to single-engine and twin-engine aircraft used for flight training was conducted for material concerning aerodynamic theory, the purpose of high lift devices, types of high lift devices, procedures for the use of flaps, and flap management.

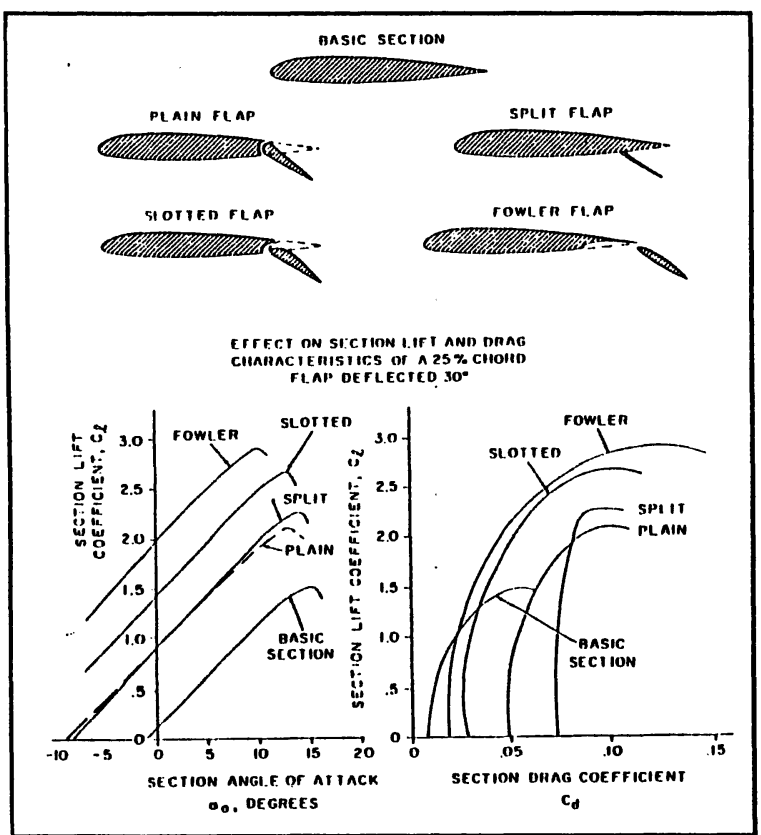

Figure 1 Effect of Flaps on Lift and Drag Coefficients

Source: Hurt, 1965; Modified by Kluga

\section{Aerodynamic Theory}

All high-lift devices increase the value of the maximum lift coefficient $\left(C L_{M A X}\right)$. Two common ways to increase $C L_{\text {MAX }}$ are to increase the camber of the airfoil or to delay the boundary layer separation. The usual method of increasing the camber is through the use of trailing-edge flaps (DAF, 1970). The deflection of Rearche, Vilap Norodduces the effect of a large amount of camber added well aft on the chord. As shown in Figure 1, the basic effect of the camber added well aft on the chord causes a significant increase in $\mathrm{CL}_{\text {MAX }}$, moves the zero lift angle-of-attack to a greater negative value, and causes the drag to increase greatly (Hurt, 1965).

The method used to delay the boundary layer separation is to increase the boundary layer energy. One such method is through the use of leading edge devices. High lift leading edge devices consist of slots, slats, and leading edge flaps. Slots and slats conduct the flow of high energy air into the boundary layer on the upper surface and delay airflow separation to some higher angle of attack and higher value of $\mathrm{CL}_{\mathrm{MAX}}$. Slots and slats cause the lift coefficient versus angle-of-attack curve to be extended. Refer to Figure 2. Slots

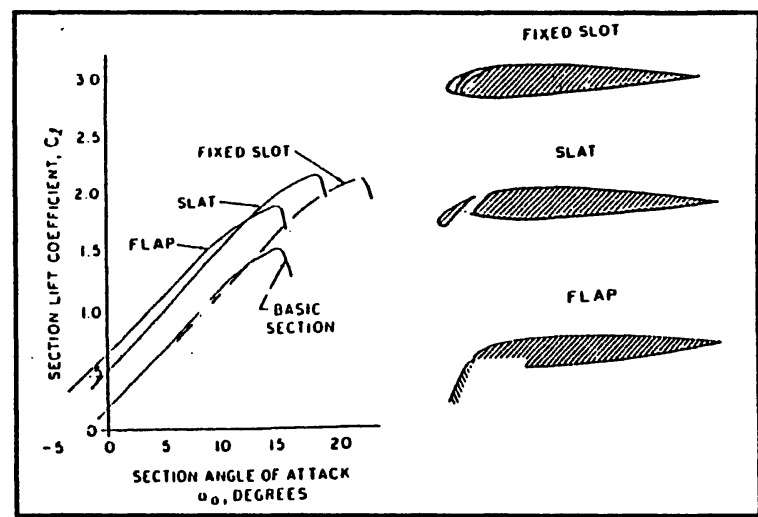

Figure 2 Stall Speeds and Takeoff Speeds Source: Hurt, 1965; Modified by Kluga

increase boundary layer energy only, slats increase boundary layer energy and increase the local camber, and leading edge flaps increase the local camber only (Kluga, 1985a). One main disadvantage of slots is the high stall angle created. The airplane must approach for a landing in an extreme nose-up attitude which promotes reduced visibility (Talay, 1975).

The deflection of a trailing-edge wing flap causes large nose down moments which 


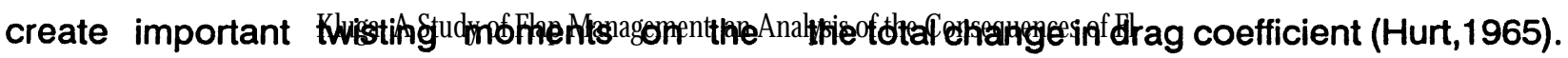
aircraft structure and pitching moments that must be controlled with the horizontal tail. The types of flap which produce the greatest increases in $\mathrm{CL}_{\text {MAX }}$ usually cause the greatest twisting moments. The Fowler flap causes the greatest change in twisting moment and the split flap causes the least. However, the use of leading-edge slot or slat causes only a negligible change in the pitching moment (Hurt, 1965).

Small initial deflections of wing flaps cause noticeable changes in $\mathrm{CL}_{\text {MAX }}$ without large changes in drag coefficient. Large wing flap deflections past 30 to 35 degrees do not create the same rate of change of $\mathrm{CL}_{\text {MAX }}$, but do cause greater changes in the drag coefficient. As shown in Figure 3, in most airplanes the first 50 percent of wing flap deflection causes more than half of the total change in $\mathrm{CL}_{\text {MAX }}$ and the last 50 percent of wing flap deflection causes more than half of

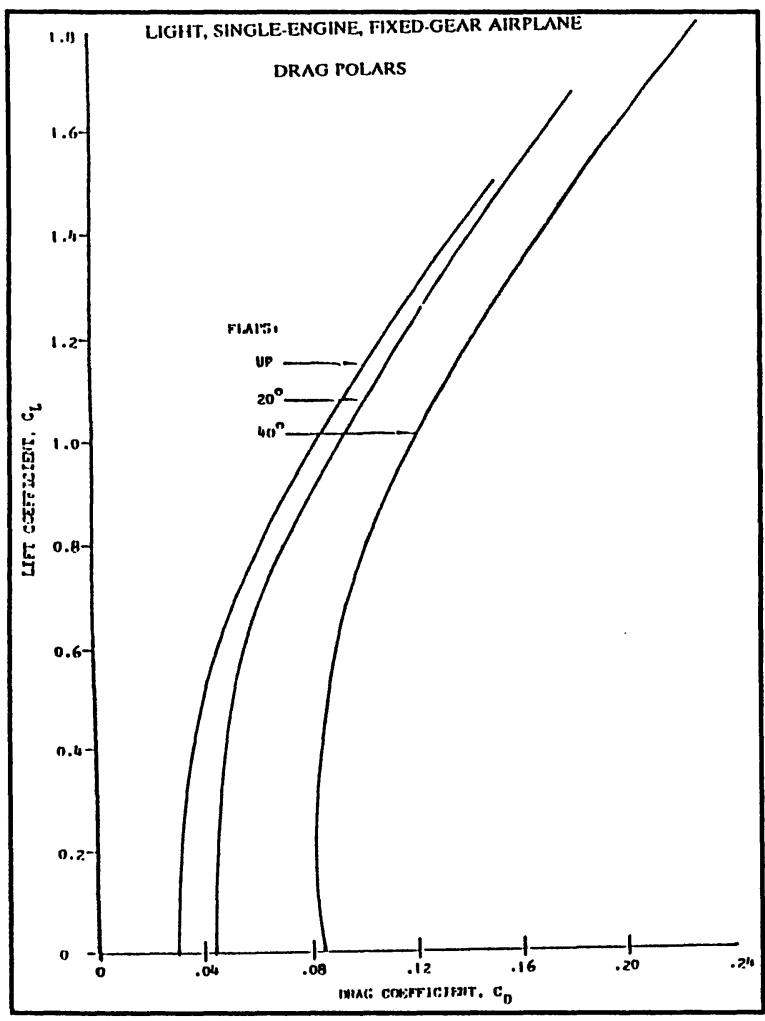

Figure 3 Flap Retraction at Takeoff Speed Source: Hurt, 1965; Modified by Kluga

\section{Purpose of High Lift Devices}

The Federal Aviation Administration (FAA) (Department of Transportation [DOT], 1980) stated that wing flaps have two functions. First, they permit a slower landing speed and decrease the required landing distance. Second, they permit a comparatively steep angle of descent without an increase in airspeed. Because of this, it is possible to safely clear obstacles during landing approaches to small fields. Jeppesen Sanderson (1988a) explained that when used properly, wing flaps increase the lifting efficiency of the wing, permit an airplane to fly at slower approach speeds, and to touchdown at slower landing speeds. Kershner (1981) stated that the primary purpose of flaps is to decrease landing speed; the rate of descent is steeper, too, but with the approaches-to-airport obstruction requirements, this is not as important as it once was, except for short field obstacle clearance.

Hurt (1965) explained that the primary purpose of high lift devices is to increase the maximum coefficient of lift of the airplane and reduce the stall speed. Takeoff and landing speeds are consequently reduced. In the Air Training Command Manual (Department of the Air Force [DAF], 1970), it is explained that the thin, modern, high-speed, swept airfoil is an inefficient slow-speed lift producer. This type of wing and planform results in high stall speeds and unacceptable landing speeds. The use of high lift devices can increase the maximum value of the coefficient of lift $\left(\mathrm{CL}_{\mathrm{MAX}}\right)$, lower the stall speed, and lower landing and takeoff speeds.

In the clean configuration, aircraft with high-speed wings have higher stall speeds, higher approach speeds, and require longer runways for landing roll out. High lift devices lower the stall speed of the high speed wing making the wing efficient for low speed 
operation. High lift Journal of Aviation/Aerospace Education "spread" between stall speed and cruise speed. For high speeds, these devices can be retracted leaving the wing at its original high speed design. Additionally, wing flaps decrease the airplane's pitch attitude, thereby improving visibility for landing (Kumpula, 1980). Types of High Lift Devices

The high lift devices applied to the trailing edge of an airfoil consist of a flap, as shown in Figure 1, which is usually 15 to 25 percent of the chord. The plain flap is a simple hinged portion of the trailing edge. The effect of the camber added well aft on the chord causes a significant increase in $\mathrm{CL}_{\text {MAX }}$. In addition, the zero lift angle changes to a more negative value and the drag increases greatly (Hurt, 1965).

The split flap consists of a plate deflected from the lower surface of the airfoil and produces a slightly greater change in $\mathrm{CL}_{\text {MAX }}$ than the plain flap. A much larger change in drag results because of the greater turbulent wake produced by this type of flap (Hurt, 1965)..

The slotted flap is similar to the plain flap, but the gap between the main airfoil section and the flap leading edge is given specific contours. High energy air from the lower surface is ducted to the flap upper surface. This high energy air accelerates the upper surface boundary layer and delays airflow separation to some higher lift coefficient. The slotted flap can cause much greater increases in $\mathrm{CL}_{\text {MAX }}$ than the plain flap and the split flap and the airfoil section drags are much lower (Hurt, 1965).

The Fowler flap arrangement is similar to the slotted flap. The difference is that the deflected flap segment is moved aft along a set of tracks which increases the chord and effects an increase in the wing area. The Fowler flap is characterized by large increases in $C L_{\text {MAX }}$ with minimum changes in drag (Hurt, 1965).
Research high lifit devices, as shown in Figure 2, are applied to the leading edge of an airfoil section and consist of slots, slats, and leading edge flaps. The leading-edge slot is a fixed slot through the wing which vents the high energy air from the lower surface over the upper surface of the wing (DAF, 1970). The fixed slot delays airflow separation on the upper surface to some higher angle of attack and value of maximum lift coefficient. The fixed slot has no effect on the camber (Hurt, 1965).

The leading-edge slat is flush when retracted and moves forward and down on tracks when extended. When extended, the slat increases the local camber and increases the boundary layer energy on the upper surface. This allows the airfoil section to continue to a higher angle of attack and a higher value of $\mathrm{CL}_{\mathrm{MAX}}$ (Kluga, 1985b). The leading-edge flap is hinged at the leading edge and simply deflects down and forward. The leading-edge flap increases the local camber only and increases $\mathrm{CL}_{\text {MAX }}$ with a slight change in the angle of attack (DAF, 1970).

\section{Procedures For The Use of Wing Flaps}

Takeoff. The Cessna Information Manuals for both the Model 172P Skyhawk (1984a) and the Model T303 Crusader (1984b) states that the normal takeoff flap setting is 0 to 10 degrees and that flap deflections of more than 10 degrees are not recommended. Flaps must not be retracted until obstacles have been cleared and a safe flap-retraction speed has been reached. The Piper (1978) Information Manuals for both the Model PA-28-161, Cadet, (1988) and the Model PA-44-180, Seminole, (1978) recommend flaps up for normal takeoffs and 25 degrees of flaps for short field takeoffs. Flaps should be retracted slowly after accelerating to proper climb speed. The Mooney (1989) M20J Information Manual states that the normal takeoff flap setting is 15 degrees. After takeoff, wing flaps are to be 


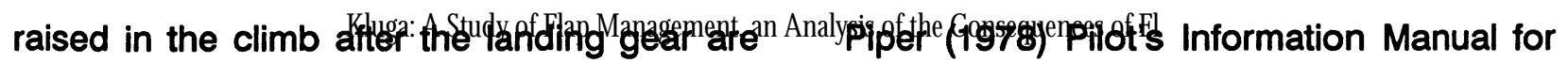
retracted and after clearing obstacles.

Landing and Balked Landing (Go Around). The Cessna (1984a) Information Manual for the Skyhawk states that normal landing approaches can be made with any flap setting desired and that surface winds and air turbulence are usually the primary factors in determining the most comfortable approach speeds. For a short field landing in smooth air conditions, the approach should be made at $61 \mathrm{KIAS}$ with 30 degrees flaps using enough power to control the glide path. Slightly higher approach speeds should be used under turbulent air conditions. When landing in a strong crosswind, the minimum flap setting required for the field length should be used. In a balked landing (go-around) climb, the flap setting should be reduced to 20 degrees immediately after full power is applied. If obstacles must be cleared during the go-around climb, the flap setting should be reduced to 10 degrees and a safe airspeed maintained until the obstacles are cleared. After clearing any obstacles, the flaps may be retracted as the airplane accelerates to the normal flaps-up climb speed.

For the Cadet, the Piper (1988) Information Manual explains that the amount of flap used during landings and the speed of the aircraft at contact with the runway should be varied according to the landing surface and conditions of wind and airplane loading. It also asserts that it is generally good practice to contact the ground at the minimum possible safe speed consistent with existing conditions. Normally, the best technique for short and slow landings is to use full flaps and enough power to maintain the desired airspeed and approach flight path. In high wind conditions, particularly in strong crosswinds, it may be desirable to approach the ground at higher than normal speeds with partial or no flaps.

the Seminole states that the flap position for landing will depend on runway length and surface wind. It goes on to say that full flaps will reduce the stall speed during final approach and will permit contact with the runway at a slower speed. For normal landing, it is suggested to approach with full flaps (40 degrees) and partial power until shortly before touchdown. The approach should be made with full flaps at 75 KIAS for a short field landing. Immediately after touchdown the flaps should be raised. If a crosswind or high-wind landing is necessary, the approach should be made with higher than normal speed and with zero to $\mathbf{2 5}$ degrees of flaps, and immediately after touchdown the flaps should be raised. If a go-around from a normal approach with the airplane in the landing configuration becomes necessary, takeoff power should be applied to both engines, a positive climb attitude should be established, and the flaps and landing gear should be retracted.

For the Crusader, Cessna (1984b) Information Manual stipulates that for short field landings, a power approach should be made at $81 \mathrm{KIAS}$ with full flaps. A wing-low drift correction technique with wing flaps fully extended is the preferred method of performing crosswind landings. It also asserts that the maximum crosswind velocity is generally dependent upon pilot proficiency rather than airplane limitations. In a balked landing (go-around) climb, the wing flaps should be retracted immediately after full power is applied.

The Mooney (1989) M20J Information Manual states that for approach to landing, the wing flap setting is as desired by the pilot. For a normal landing, the wing flaps should be full down (33 degrees) and final approach speed should be $69 \mathrm{KIAS}$. For maximum performance landing, full flaps and final approach speed of 
63 KIAS should be used. For crosswind landings, normal landing procedures should be used, except an approach speed appropriate for the wind conditions should be maintained. Landing information for reduced flap settings is not available. The procedure recommended for balked landing (go-around) is: airspeed - 65 KIAS; flaps - after climb is established, raise to takeoff position (15 degrees); airspeed -. accelerate to $70 \mathrm{KIAS}$; flaps - retract; and airspeed - accelerate to 90 KIAS.

According to Kershner (1981) some instructors advocate the use of full flaps on every approach for every airplane, but local conditions may not make this practicable. Kershner also states that the amount of flaps to use is dictated by the particular conditions. For the Cessna 150, an airplane with a low stall speed, the last 20 degrees of flaps only lowers the stall speed $1 \mathrm{mph}$, but may not give good go-around characteristics under certain conditions. His suggested flap settings for the Cessna 150 are: (a) normal landing - 20 degrees, landing at $49 \mathrm{mph}$, easy go-around; (b) short or soft field landing - 40 degrees landing at $48 \mathrm{mph}$, a go-around is little more complicated, and (c) gusty air and crosswind - 20 degrees or less. The suggested flap setting during the presolo training period in the Cessna 150 is to set 20 degrees in one move at the abeam position and maintain 20 degrees for the entire approach and landing. Further flap adjustments would require continual pitch changes and would divert the student's attention from the runway and the approach.

Kumpula (1988) provides general rules for the use of flaps: (a) for landing at normal touchdown speed, use full flaps, and (b) for landing at higher than normal touchdown speed, use a reduced flap setting appropriate to the desired touchdown speed. He also makes the following suggestions for the use of higher approach and touchdown speeds:
1. For turbulence in the approach zone, use less than full flaps and a higher approach speed. For the higher approach speed, use the normal approach speed for that flap setting plus one-half of the gust velocity.

2. For landings in a light crosswind (up to crosswind component of $20 \%$ of stall speed in the landing configuration), use full flaps and -normal approach speeds. For landings in a strong crosswind (greater than crosswind component of $20 \%$ of stall speed), if no other runway more directly into the wind is available, use less than full flaps and a higher stall speed (within reason) so that the maximum slip angle can handle the crosswind.

3. For turbulence in the touchdown zone, use less than full flaps and a higher touchdown speed (normal plus one-half gust) because the vertical gust could cause the airplane to stall at a higher airspeed.

\section{Flap Management}

The FAA (DOT,1969) Flight Instructor's Handbook states that the sudden retraction of the flaps in flight will result in an abrupt loss in altitude, unless the angle of attack is increased as the flaps are retracted. With careful control coordination, it is possible to retract the flaps for a go-around at any speed above the flaps-up stalling speed. The retraction of flaps in flight near the ground should be accomplished with great care, however. No conventional airplane will climb more rapidly with the flaps extended than it does with them retracted. Most airplanes will, however, takeoff with a shorter ground run and climb at a steeper angle with the flap setting recommended by the airplane flight manual for takeoff. The use of flap extension greater than that recommended by the airplane flight manual may actually retard, rather than assist, the takeoff and climb.

Jeppesen (1988b) described the procedure for go-around: If a go-around with full flaps is 
required, the procedurtes frecoffinfermldeapemethe pilot's operating handbook should be followed. After adding all available power, the flaps should be retracted to an intermediate setting, if required, but entry into a normal climb attitude should not be attempted immediately. Instead, the straight-and-level, slow flight attitude should be used to maintain the airplane's present altitude. Then, the best angle-of-climb speed should be maintained until all obstacles are cleared. Acceleration to the best rate-of-climb speed should be accomplished followed by slowly retracting the remaining flaps. During the initial stages of the go-around, extra caution is required. An attempt to raise the flaps immediately may result in a stall. Suddenly raising all of the flaps can cause the airplane to descend to the ground.

According to Hurt (1965), the management of the high lift devices on an airplane is an important factor in flying operations. The leading edge devices are usually of little concern and cause few complications since relatively small changes in drag and pitching moments take place. However, the wing flaps must be properly managed by the pilot to take advantage of the capability of such a device. When an airplane takes off with the flaps extended, the pilot should not completely retract the flaps until the airplane has sufficient speed. If the flaps are retracted prematurely at insufficient airspeed, maximum lift coefficient of the clean configuration may not be able to support the airplane and the airplane will sink or stall.

Additionally, Dole (1981 and 1985), DOT (1977 and 1980), Kershner (1976), DAF (1979), Perkins (1949), and Jeppesen Sanderson (1976) were consulted with reference to high lift devices, and these sources present little that differs from those sources cited above.

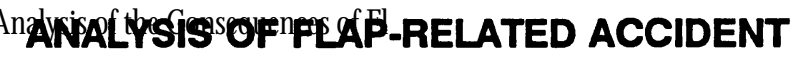
STATISTICS

An analysis of the NTSB Briefs of Accidents for the years 1983 to 1988 inclusive with flaps as a cause/factor determined that five types of flight operations were involved. These operations included (a) takeoff (both normal and high performance), (b) balked landing (go-around), (c) normal landing, (d) emergency landing, and (e) other flight operations. For each year, the accidents were subdivided into the five conditions of flight, tabulated, and totalled. The results are shown in Table 1. A total of $\mathbf{2 3 2}$ accidents occurred during the sixyear period or one accident every 9.45 days. This average varied from a high of 54 accidents in 1983 to a low of 22 accidents in 1988. The condition of flight during which the highest number of accidents occurred proved to be the balked landing (go-around). For the six-year period, $40.1 \%$ of the accidents occurred during the go-around, $29.3 \%$ during takeoff, $16.8 \%$ during normal landings, $12.5 \%$ during emergency landings, and $1.3 \%$ during other conditions of flight.

The data were analyzed further to determine the number of training and non-training flights involved. The results are tabulated and show that $29.3 \%$ of the accidents $(11.2 \%$ solo and $18.1 \%$ dual) occurred during training flights and $70.7 \%$ were during non-training flights.

The accident data were subdivided further into types of injuries: fatal, serious, minor, and none. For the six year period, a total of 702 persons were involved. Of that total, 446 received injuries, of which 258 were fatal and 73 were serious. Over one-third, $36.7 \%$, of the injuries were fatal. On the average, there were 1.1 fatalities per accident.

The Accident Briefs were analyzed further to determine what aspect of flap mismanagement was involved. The two predominant causes of 
Flap-Related Accidents

\begin{tabular}{lllllllll}
\hline Year: & 83 & 84 & 85 & 86 & 87 & 88 & TOTALS & (\%)
\end{tabular}

\section{Operation:}

Takeoff

$\begin{array}{lllllll}12 & 16 & 12 & 7 & 15 & 6 & 68\end{array}$

(29.3\%)

Go-around

2420

13

$12 \quad 12 \quad 12$

93

Normal Landing 13

Emergency

5

Other

0

Totals

$\begin{array}{lllllll}54 & 44 & 38 & 25 & 49 & 22 & 232\end{array}$

Type Training:

$\begin{array}{lcccccccc}\text { Dual } & 4 & 5 & 5 & 4 & 6 & 2 & 26 & (11.2 \%) \\ \text { Solo } & 9 & 7 & 6 & 6 & 6 & 8 & 42 & (18.1 \%) \\ \text { Non-training } & 41 & 32 & 27 & 15 & 37 & 12 & 164 & (70.7 \%)\end{array}$

$\begin{array}{llllllll}\text { Total } & 54 & 44 & 38 & 25 & 49 & 22 & 232\end{array}$

Injuries:

$\begin{array}{lcccccccc}\text { Fatal } & 24 & 8 & 16 & 2 & 202 & 6 & 258 & (36.7 \%) \\ \text { Serious } & 14 & 12 & 15 & 12 & 15 & 4 & 72 & (10.3 \%) \\ \text { Minor } & 24 & 17 & 16 & 17 & 30 & 11 & 115 & (16.4 \%) \\ \text { None } & 58 & 53 & 39 & 31 & 53 & 23 & 257 & (36.6 \%) \\ & & & & & & & & \\ \text { Totals } & 120 & 90 & 86 & 63 & 300 & 44 & 702 & \end{array}$

Note: 1987 includes the DC-9-82 accident August 16 at Detroit with 156 fatal, 2 serious, and 4 minor injuries.

Table 2

Flap-Related Accidents by Cause

\begin{tabular}{lllll}
\hline & Takeoff & Go-around & $\begin{array}{l}\text { Normal } \\
\text { Landing }\end{array}$ & $\begin{array}{l}\text { Emergency } \\
\text { Landing }\end{array}$ \\
\hline Cause: & & & & \\
Incorrect Amount & 50 & 49 & 20 & 17 \\
Incorrect Procedure & 17 & 44 & 17 & 11 \\
Other & 1 & 0 & 2 & 1 \\
Total & 68 & 93 & 39 & 29 \\
\hline
\end{tabular}




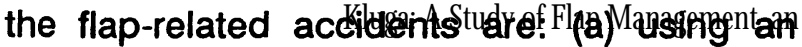
incorrect amount of flaps, and (b) using improper procedures for the raising or lowering of the flaps. The results are shown in Table 2.

\section{FLIGHT TEST DATA}

In order to graphically show, prior to flight test, the effect of wing flaps on aircraft performance, data were computer-generated for a generic light single-engine airplane and curves were plotted of (a) brake horsepower (BHP) versus velocity, (b) thrust horsepower (THP) versus velocity, and (c) thrust (drag) versus velocity and are shown in Figure 4.

With flaps down there is a definite increase in BHP required, THP required, and thrust required (drag) to fly at each airspeed; a considerable reduction in excess BHP, THP, and thrust and significantly reduced climb performance; and a reduction in maximum level-flight speed, $\mathrm{V}_{\mathrm{MLF}}$. The curves also show that this airplane enters the region of reverse command at airspeeds below 60 KCAS.

The flight tests were conducted in Cessna $172 \mathrm{~N}$ under the following conditions: weight $=$ 2025 Ibs., CG moment index $=82.5$, density altitude $=2,687 \mathrm{ft} ., V_{Y}$ (clean) pitch attitude $=$ 5 deg., and $V_{X}$ (clean) pitch attitude $=8 \mathrm{deg}$. In each case, at a final approach speed of 60 KIAS, full power was applied, the carburetor heat was set at cold, and the pitch attitude set for $V_{X}$ or $V_{Y}$.

During the go-around flight tests, several different flap settings as well as various methods of retraction were investigated. During the normal recommended go-around for the $\mathrm{C}$ $172 \mathrm{~N}$, the flaps were retracted from 40 to 20 degrees and the pitch attitude set and maintained throughout for $V_{Y}$. The rate of climb stabilized at 350 FPM and the airspeed accelerated to $68 \mathrm{KIAS}$. When the flaps were retracted from 20 to 10 degrees, the rate of climb increased to 650 FPM and the airspeed accelerated slightly.

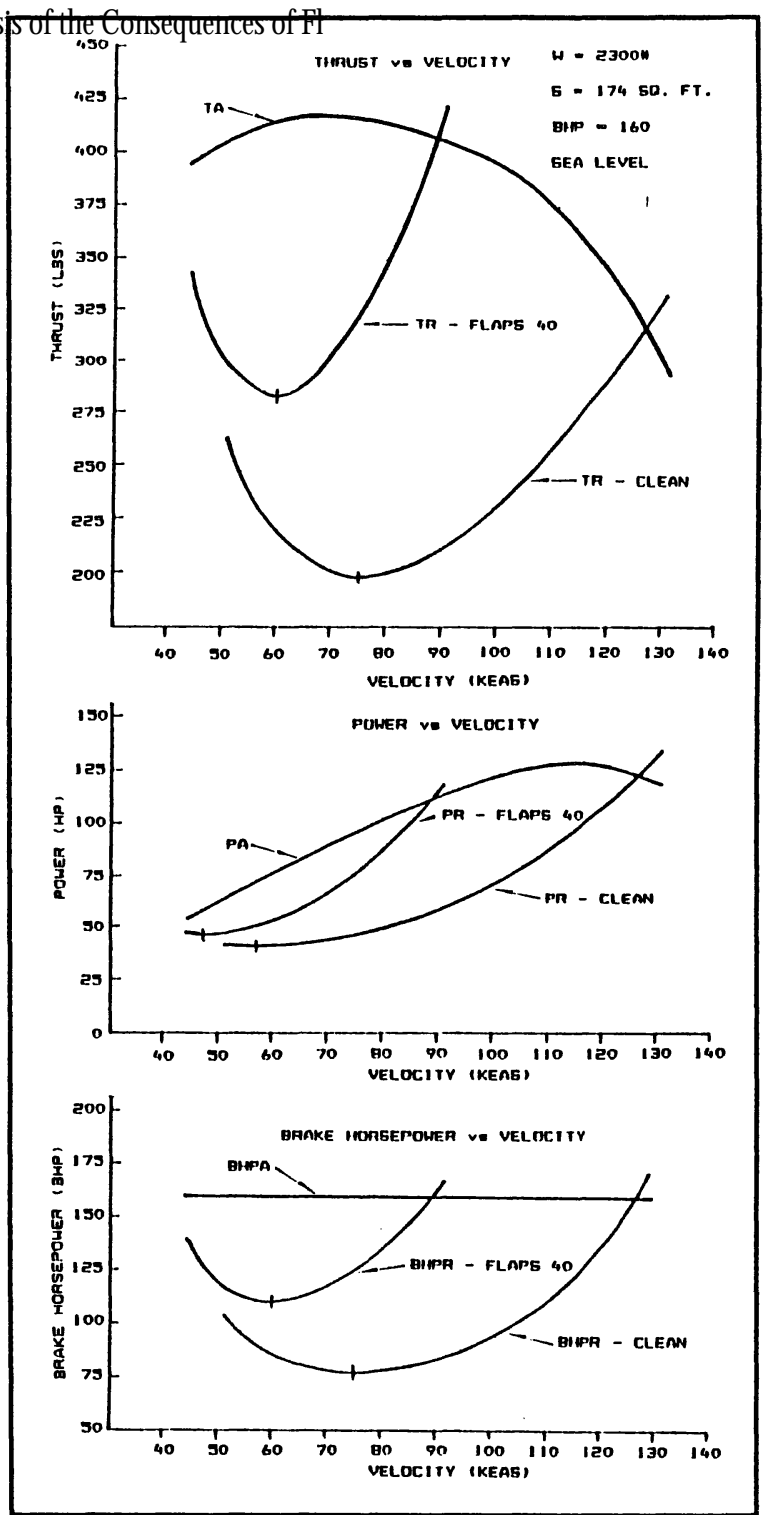

Figure 4 Flap Retraction at Flap Retraction Speed

Source: Hurt 1965; Modified by Kluga

A go-around with flaps retracted to 30 degrees was then attempted. The pitch attitude was set for $V_{Y}$ and maintained throughout. The rate of climb stabilized at 350 FPM and the air speed decelerated from 60 to 55 KIAS. When repeated using a pitch attitude for $V_{x}$, the rate of climb initially was 400 FPM, but gradually decreased to 300 FPM and the airspeed decelerated from 60 to 44 KIAS.

The next flap configuration was a go-around with $\mathbf{4 0}$ degrees of flaps. The pitch attitude was set for $\vec{V}_{Y}$ and the initial rate of climb of 400 


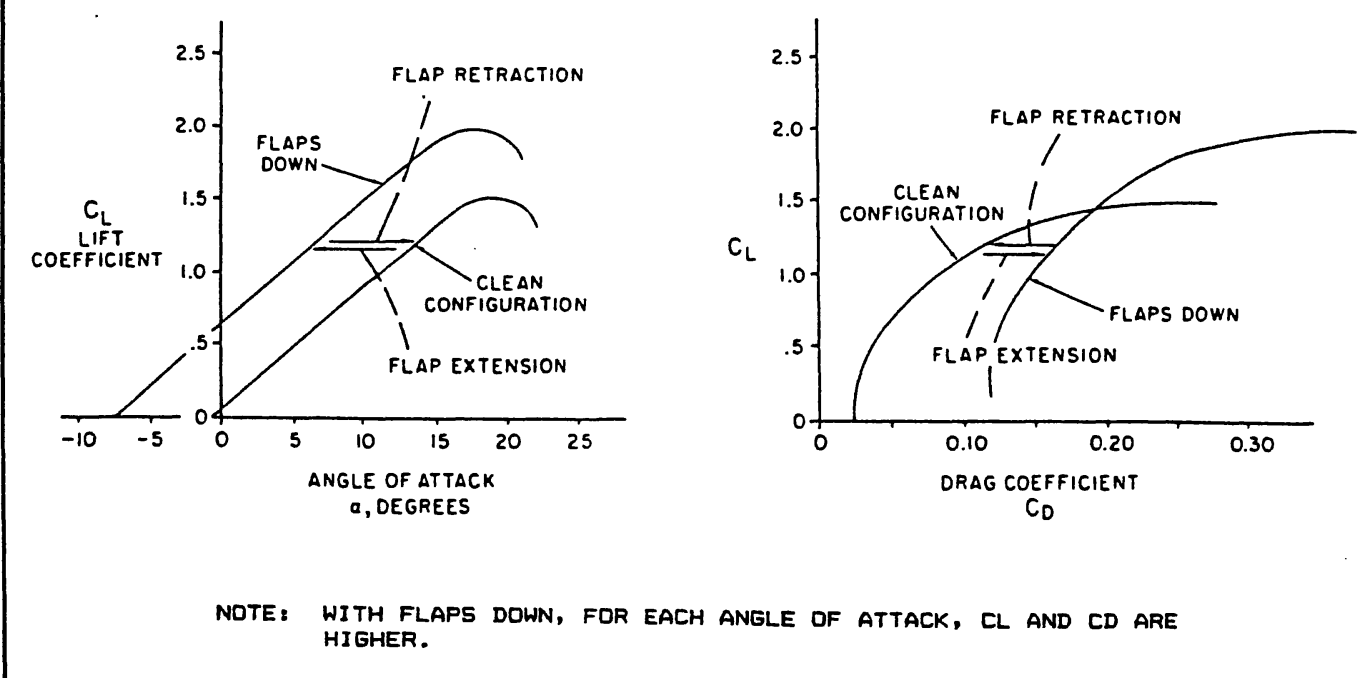

Figure 5 Proper Retraction Procedure

Source: Hurt, 1965; Modified by Kluga

FPM decreased to 300 FPM. The airspeed decelerated from 60 to 55 KIAS. When repeated using a pitch attitude for $V_{x}$, the initial rate of climb of 400 FPM decreased to 200 FPM. The airspeed decelerated from 60 to 35 KIAS and the stall warning horn sounded.

The final scenario was a go-around with 40 degrees of flaps which would be raised all at once. With the pitch attitude set for $V_{x}$, the airspeed decelerated to $35 \mathrm{KIAS}$. At this point, the flaps were raised all at once and the elevator control pressure was not changed. A strong nose-down pitching moment was experienced and the pitch attitude decreased. The airspeed accelerated and the aircraft lost altitude. When repeated, the flaps were raised all at once and the pitch attitude was held constant for $V_{x}$. In this case, the airspeed accelerated slowly, the rate of climb decreased to zero, and aircraft did not lose altitude.

\section{DISCUSSION: FLAP MANAGEMENT}

Although various textbooks explain the purposes of flaps differently, the functions of the flaps are explained adequately for the private and commercial pilot in DOT (1980), Jeppesen Sanderson (1988a) and Kershner (1976). The descriptions of trailing edge flaps contained in these textbooks provide adequate information.

The manufacturer's aircraft information manuals reviewed provide instructions for proper flap settings for normal and high performance takeoffs; however, only one (Cessna, 1984a) specifically states that more than 10 degrees of flaps are not approved for high performance takeoffs. Concerning landing and go-around, the manufacturer's aircraft information manuals reviewed provide instructions for normal, crosswind, and balked landings with one exception: the Piper Cadet manual does not set forth the procedure for the balked landing/go-around. None explain why it is required to retract the flaps from the full-down position to an intermediate position immediately after full power is applied for the go-around.

FAA Flight Instructor's Handbook (DOT, 1969) contains a complete explanation concerning the retraction and extension of flaps. However, the FAA publication has been superseded by the Aviation Instructor's Handbook (DOT, 1977), in which there is no mention of the proper procedure for the use of flaps. In addition, Jeppesen Sanderson (1988b) 
provides a very good

use of flaps in a go-around.

Textbooks by the FAA (DOT, 1980), Jeppesen Sanderson (1988a and 1988b), and Kershner (1976 and 1981) do not include explanations of the aerodynamic theory of high lift devices. Hurt (1965) and DAF (1970) do explain the basic aerodynamics theory of high lift devices.

To clarify several key points concerning flap management, a detailed explanation follows. Figure 5 presents lift and drag curves of a typical airplane in the clean and flaps-down configurations. Note that with flap extension the lift coefficient versus angle-of-attack curve is elevated and for every angle of attack, the value of the lift coefficient is higher. Referring to the lift coefficient versus drag coefficient curves, with flap extension, for every value of lift coefficient, the value of drag coefficient is also higher.

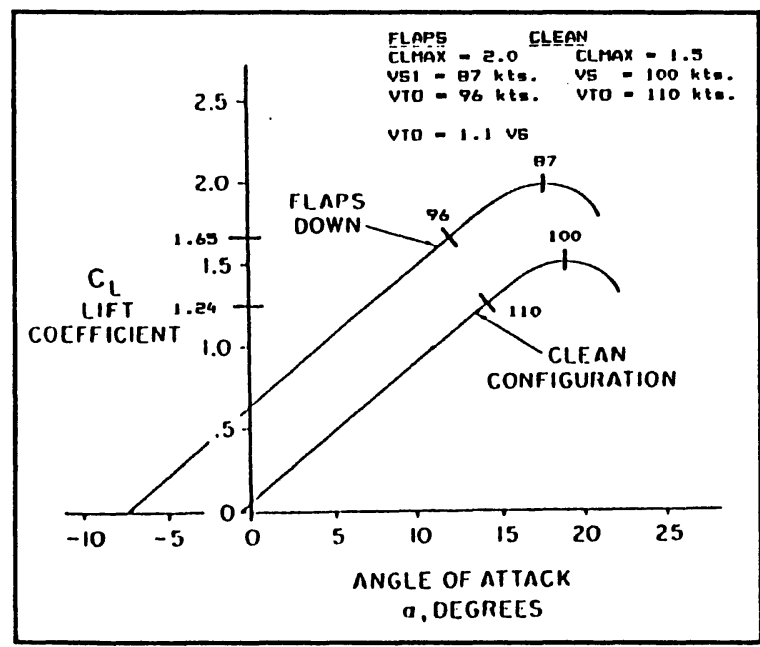

Figure 6 Lift and Drag Coefficient Changes with Flap Retraction Source: Hurt, 1965; Modified by Kluga

Refer to Figure 6. In order to appreciate some of the factors involved in flap management, assume that the airplane has just taken off or executed a go-around and the flaps are extended. An analysis can be made of what is happening with respect to airspeed, angle of attack, and lift coefficient, CL, during clean configuration, stall speed, $V_{S}$, is 100 knots at a maximum lift coefficient, $C L_{\text {MAX }}$, of 1.5 and that the takeoff speed (clean) is $10 \%$ above stall speed at 110 knots at a lift coefficient of 1.24. In the flaps-down configuration, stall speed, $V_{S_{1}}$, is 87 knots at a $\mathrm{CL}_{\text {MAX }}$ of 2.0 and takeoff speed (flaps) is 96 knots at a CL of 1.65 .

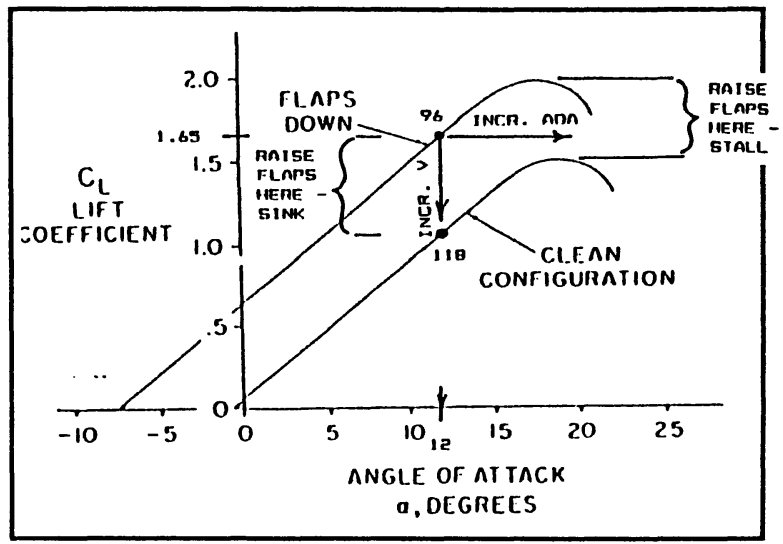

Figure 7 Flap Extension

Source: Hurt, 1965; Modified by Kluga

\section{Go-around Options}

Refer to Figure 7. At the flaps-down takeoff/go-around speed of 96 knots, a lift coefficient of 1.65 is needed; therefore, the aircraft must fly at an angle of attack of 12 degrees to obtain the required value of $\mathrm{CL}$. If the flaps are retracted at 96 knots, the pilot has two options: (a) remain at the same value of lift coefficient and airspeed or (b) remain at the same angle of attack. A third option is a combination of the first two, but to simplify the explanation of what is happening, the discussion will be limited to options (a) and (b).

Exploring option (a), to remain at the same value of lift coefficient and retract the flaps is not possible because this is beyond the maximum lift coefficient in the clean configuration. Therefore, if the flaps are retracted at the flaps-down takeoff/go-around speed in this aircraft, the airplane will stall if it attempts to stay at the same value of lift 
coefficient.Option (b) is not much better; i.e., to remain at the same angle of attack and accelerate. Even with a very high thrust-to-weight ratio, no airplane can stay at the same angle of attack and instantaneously accelerate from 96 to 118 knots. Therefore, in this situation, this airplane will not be able to maintain level flight and will descend. If the angle of attack is decreased in an attempt to accelerate, the airplane will descend even fister because the lower angle of attack will develop a lower lift coefficient which means the airplane must go even faster than 118 knots to maintain level flight. Either of these two options is very dangerous because either to stall or to set up a rate of descent soon after takeoff or while executing a go-around could result in a collision with the ground.

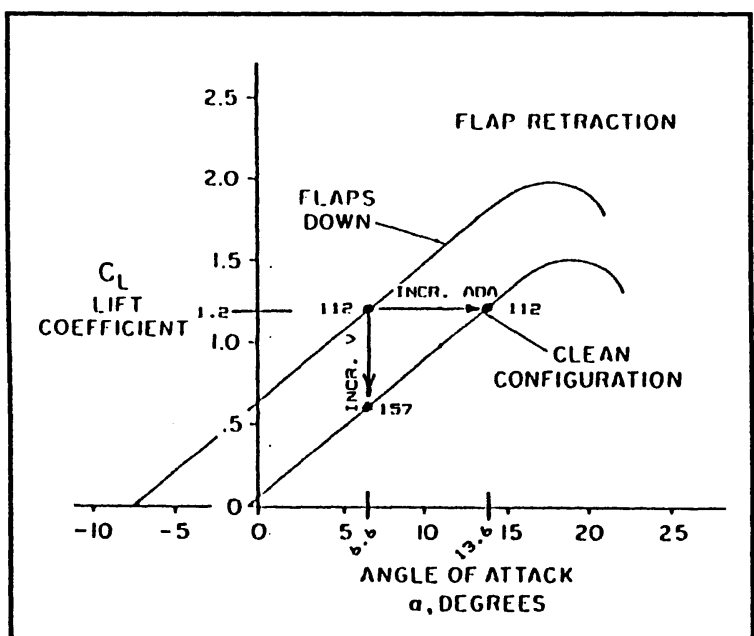

Figure $8 \mathrm{CL}_{\mathrm{mAx}}$ and $\mathrm{CD}$ Changes with Flap Extension Source: Kluga, 1985a

For the airplane represented in Figure 8 it is recommended that a lift coefficient of 1.2 be used for flap retraction. The airspeed necessary to fly at that $C L$ is 112 knots (either in the clean or flaps-down configuration); however, while the airspeed is the same for that value of $C L$, the angle of attack is not the same. The angle of attack with flaps down is 6.6 degrees and clean is 13.6 degrees. At the recommended flap-retraction speed of 112 knots, the pilot again has two options while retracting the flaps: (a) to remain at 112 knots and increase the angle of attack from 6.6 to 13.6 degrees in order to maintain the same value of $\mathrm{CL}$ or, (b) to remain at the same angle of attack of 6.6 degrees and accelerate from 112 knots to 157 knots. Of course, this is not practical in an instant; so, the airplane would descend.

A third option available is to use a combination of (a) and (b), increase the angle of attack and accelerate while retracting the

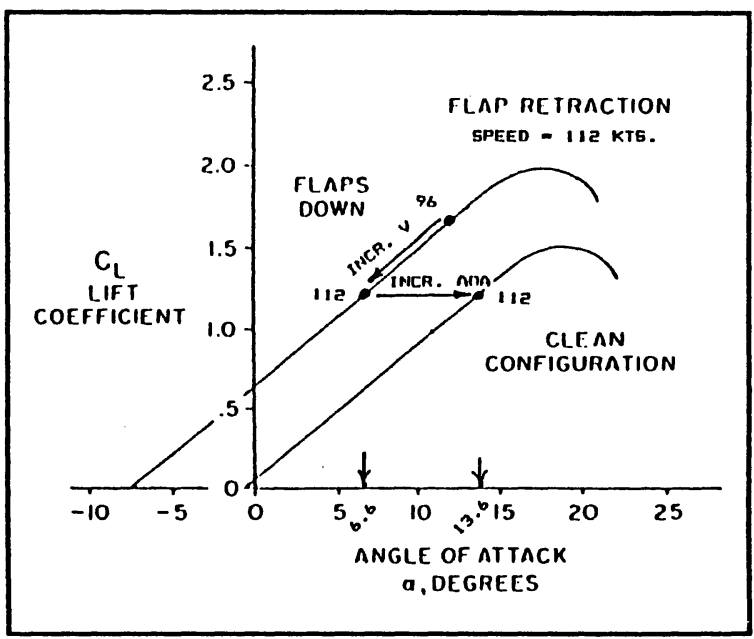

Figure 9 Proper Retraction Procedure

Source: Hurt, 1965; Modified by Kluga

flaps in increments. As shown in Figure 9, the proper procedure for flap retraction is: if the takeoff/go-around speed is $10 \%$ above stall speed with flaps down, the airplane must be accelerated with flaps down (increasing airspeed and decreasing angle of attack) until the airspeed will allow safe transition from flaps down to flaps up. This safe speed is the flap retraction airspeed, which, for a $\mathrm{CL}$ of 1.2 is 112 knots. The pilot should "bleed" the flaps up and smoothly increase the angle of attack from the angle of attack flaps down to the angle of attack flaps up. If the airplane has good acceleration, the pilot can either maintain a constant airspeed and increase the angle of 


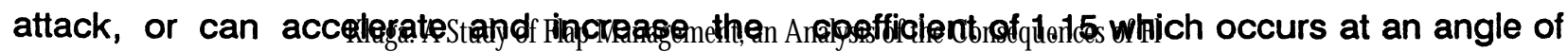
angle of attack. The required angle-of-attack change is not as great when accelerating.

Three important changes take place during flap retraction:

1. The reduction of wing camber by flap retraction changes the wing pitching moment and, for the majority of airplanes, requires retrimming to balance the nose-up moment change.

2. The retraction of wing flaps causes a reduction of drag coefficient at that lift coefficient. This drag reduction improves the acceleration of the airplane.

3. The retraction of wing flaps requires an increase in angle of attack to maintain the same coefficient of lift. If aircraft acceleration is low through the flap retraction speed range, angle of attack must be increased to prevent the aircraft from descending. This situation is typical after takeoff when gross weight, density altitude, and temperature are high. However, some aircraft have such high acceleration through the flap retraction speed range that the rapid gain in airspeed requires much less noticeable attitude change.

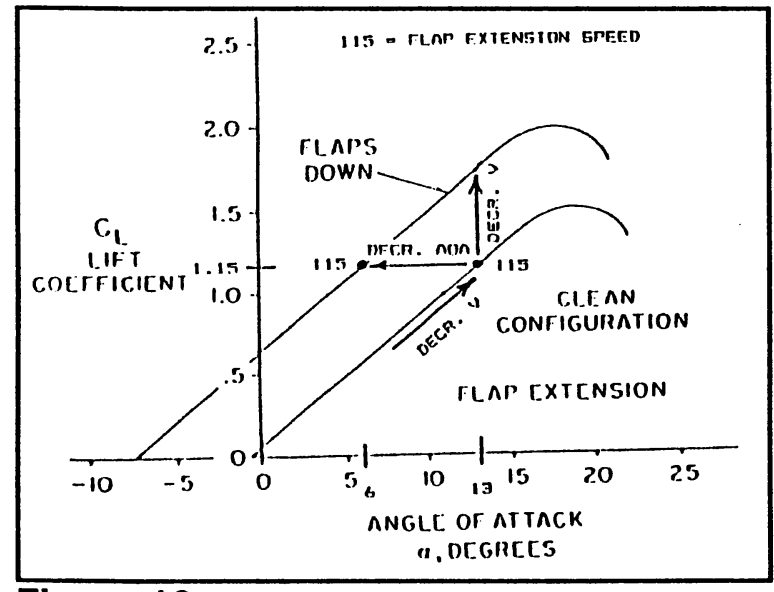

Figure 10 Flap Extension Source: Kluga, 1985a

As shown in Figure 10, prior to extending flaps, the aircraft must decelerate to or below the maximum flap extension speed. In the case of the sample aircraft, the recommended flap extension speed is 115 knots at a lift attack of 13 degrees.During flap extension, the pilot has two options: (a) to remain at the same angle of attack, or (b) to remain at the same lift coefficient and airspeed. If the same angle of attack is maintained, the $\mathrm{CL}$ will increase and the airspeed necessary to fly at that CL must decrease. In the example, the lift coefficient will increase to 1.75 and, therefore, the airspeed must decrease to 93 knots to maintain altitude. If the same lift coefficient and airspeed are maintained, the angle of attack must decrease from the angle of attack clean (13 degrees) to the corresponding angle of attack for that $\mathrm{CL}$ with flaps (6 degrees) to maintain a constant altitude. In either case, the drag coefficient corresponding to the $\mathrm{CL}$ of 1.15 will increase as the flaps are extended. With the extension of flaps, there also will be a pitching moment change.

Extending the flaps will cause the following changes to take place (Hurt, 1965):

1. Typically, lowering the flaps requires retrimming to balance the nose-down moment change.

2. The increase in drag requires a higher power setting to maintain airspeed and altitude.

3. The angle of attack required to produce the same lift coefficient is less; therefore, flap extension tends to cause the airplane to "balloon".

4. An additional factor, which must be considered when rapidly accelerating after takeoff or when lowering the flaps for landing, is the limit airspeed for flap extension. Excessive airspeed in the flap down configuration may cause structural damage.

\section{CONCLUSIONS}

As previously stated, there have been numerous accidents reported that have occurred through mismanagement of flaps. Most of these accidents seem to fall into four categories, while attempting or executing a go- 
around, during take-off, as a part of norma landings, and with emergency landings.

\section{Go-around}

The high number of go-around accidents may be attributed to the need to quickly transition from the high drag configuration to the high performance takeoff configuration. The curves discussed earlier for the generic light airplane -show that at final approach speed with full flaps, the aircraft is on the border of the region of reverse command or the "backside of the power curve" and that the drag increases rapidly with a decrease in airspeed once the aircraft enters this region. If an airplane is allowed to slow down into the region of reversed command, even with full power applied, the increase in drag experienced will cause the airplane to decelerate further, which was demonstrated during the flight tests in the Cessna $172 \mathrm{~N}$. During the go-around, operating with flaps set for greater than $50 \%$ of maximum deflection places the aircraft in a high drag condition and causes a significant deterioration in climb performance in close proximity to the ground.

Another factor that must be considered in flap management accidents is that raising the flaps all at once during the go-around can cause the aircraft to descend if the airspeed is slow and the elevator control pressure is not correct to counteract a nose-down pitching moment and maintain the correct pitch attitude for level flight. During the flight test in the Cessna 172N, during the go-around, the airplane was still trimmed for $60 \mathrm{KIAS}$ approach speed. When the flaps were raised all at once and the elevator control pressure was not changed, the correct pitch attitude was not maintained and the aircraft lost altitude. But when all flaps were raised suddenly and the pitch attitude for $V_{X}$ was maintained with strong elevator control pressure to counteract the pitching moment, the aircraft stopped climbing, began to accelerate, and was able to maintain altitude even though the airspeed had deteriorated to $35 \mathrm{KIAS}$ before the flaps were raised.

\section{Takeoff}

Using full flaps for high performance takeoffs in light, single-engine training airplanes is not recommended. Flap settings for high performance takeoffs are limited to $50 \%$ or less because small deflections of wing flaps cause noticeable increases in $\mathrm{CL}_{\text {MAX }}$ without a large increase in the drag coefficient. Large wing flap deflections, past 30-35 degrees, do not cause the same rate of increase of $\mathrm{CL}_{\text {MAX }}$, but do cause a much greater increase in the drag coefficient (Hurt, 1965). The increase in $\mathrm{CL}_{\text {MAX }}$ allows the airplane to become airborne at a slower airspeed and in a shorter distance. At 25 degrees or less the drag increase is kept low. At a flap setting above 30 degrees the drag increase is significant, and adversely affects the aircraft's initial climb performance.

Raising flaps too soon or all at once after takeoff can cause the airplane to descend particularly if the airspeed is low and the pitch attitude is incorrect to compensate for the shift of the lift-coefficient-versus-angle-of-attack curve from flaps down to flaps up and to counteract a nose-down pitching moment.

\section{Normal Landing}

Flap related accidents during landing were caused by using an incorrect amount of flaps or by using incorrect procedures. Using either too little or too much flap for the wind and runway conditions proved hazardous. Too little flap caused the airplanes to land long and too much flap contributed to the pilots' losing control of the airplane in high, gusty wind conditions, particularly with a crosswind. In one case, the airplane experienced too little drag and in the other, too much drag. During the landing, the airplane should touch down at the lowest possible speed consistent with the wind and turbulence conditions; therefore, for the normal landing, full flaps should be used. For 
gusty conditions, strong crosswind conditions, Emergency Landing

and high headwind conditions, less flaps and higher approach speeds should be used to avoid premature stall in the turbulent conditions, and to provide better control during strong crosswind and high headwind conditions.

Several accidents occurred because the pilot raised the flaps during the landing approach or the landing flare. This sudden change from the flaps-down to the flaps-up lift-coefficient curve caused the airplane to settle because of the pitching-moment change, and/or stall because the value of lift coefficient for the existing angleof attack suddenly decreased. Applying flaps too late has also led to accidents.

Of the flap-related accidents during emergency landings, most occurred during landings with no flaps; however, a number of accidents occurred when flaps were extended too soon or too much. Not using flaps definitely contributed to landing at a faster speed. The airplane did not contact the ground or runway at the slowest possible speed, thereby overrunning the runway or suffering greater damage when landing off airport. In cases when the flaps were extended too soon or too much, the airplane landed short of the airport. The extension of flaps increased the drag, steepened the descent, and caused the glide distance to be reduced.

\section{RECOMMENDATION}

As a result of an extensive review of the literature, a thorough analysis of the types and nature of the flap-related accidents, and an analysis of the results of the flap-related flight test, it is recommended that more emphasis be placed on the importance of the proper use of wing flaps to safety of flight, and on the high drag and pitching moment characteristics of wing flaps. The name "high-lift device" is misleading. The name should be "high lift and high drag" devices. Most of the flap-related accidents were due to the fact that the pilots concerned did not have a thorough understanding of the dual nature of high lift devices and/or proper respect for the high drag characteristics of wing flaps. Not enough emphasis is placed on the severe pitching moment changes that can occur in some types of aircraft when the wing flaps are suddenly extended or retracted.

It is recommended that aviation educators allocate more time to teaching flight students how high drag affects various flight operations, how sudden pitching moment changes can severely affect aircraft trim, and how to use flaps properly for all phases of flight operations: normal and high performance takeoffs; go-arounds; approaches and landings in normal conditions, in turbulence, in strong crosswinds, and in strong headwinds; and emergency approaches and landings.

Norbert R. Kluga, Professor of Aeronautical Science at Embry-Riddle Aeronautical University (ERAU) in Daytona Beach, Florida, is a retired Naval Aviator. Professor Kluga, a graduate of the University of Notre Dame, has a Bachelor of Science in Aeronautical Engineering. He has also earned a Master of Aeronautical Science degree from ERAU, where he teaches Aerodynamics, aircraft performance, global navigation, and instrument flight operations. 
Cessna Aircraft Company. (1984a). Information manual, 1985 model 172N. Wichita, KS: Cessna Aircraft Company.

Cessna Aircraft Company. (1984b). Information manual, 1984 model T303. Wichita, KS: Cessna Aircraft Company.

Department of the Air Force, Air Training Command. (1970). Aerodynamics for pilots.ATC Manual 51-3. Randolph Air Force Base, TX.

Department of the Air Force, Air Training Command. (1979). T-38 applied aerodynamics. ATC Study Guide/Workbook P-V4A-A-AA-SW. Randolph Air Force Base, TX.

Department of Transportation, Federal Aviation Administration. (1969). Flight instructor's handbook (rev. ed.). Washington, DC: U. S. Government Printing Office.

Department of Transportation, Federal Aviation Administration. (1977). Aviation instructor's handbook. Washington, DC: U. S. Government Printing Office.

Department of Transportation, Federal Aviation Administration. (1980). Flight training handbook AC 61-21A (rev. ed.). Washington, DC: U.S. Government Printing Office.

Dole, C. E. (1981). Flight theory and aerodynamics. New York: John Wiley \& Sons.Dole, C. E. (1985). Flight theory for pilots (rev. ed.). Redlands, CA: Charles E. Dole.

Hurt, H. H. Jr. (1965). Aerodynamics for naval aviators (rev. ed.). The Office of the Chief of Naval Operations, Aviation Training Division. NAVAIR 00-80T-80. Los Angeles, CA: University of Southern California.

Jeppesen Sanderson. (1976). Instrument/commercial pilot manual. Englewood, CO: Jeppesen Sanderson.

Jeppesen Sanderson. (1988a). Private pilot manual. Englewood, CO: Jeppesen Sanderson.

Jeppesen Sanderson. (1988b). Private pilot maneuvers manual. Englewood, CO:Jeppesen Sanderson Inc.

Kershner, W. K. (1976). The advanced pilot's flight manual (rev. ed.). Ames, IA: lowa State University Press.

Kershner, W. K. (1981). The flight instructor's manual (rev. ed.). Ames, IA: lowa State University Press.

Kluga, N. R. (1985a). Aircraft performance manual (rev. ed.). Daytona Beach, FL: Embry-Riddle Aeronautical University.

Kluga, N. R. (1985b). Supplemental classnotes; airplane performance, AS 310 (rev. ed.). Daytona Beach, FL: Embry-Riddle Aeronautical University.

Kumpula, L. L. (1988). Supplemental classnotes for basic aerodynamics (rev. ed.). Daytona Beach, FL: Embry-Riddle Aeronautical University.

Mooney Aircraft Corporation. (1989). M20J Information Manual. Kerrville, Texas: Mooney Aircraft Corporation.

Pan American Navigation Service. (1978). Airline transport pilot. (rev. ed.). Van Nuys, CA.: Pan American Navigation Service.

Perkins, C. D., \& Hage, R. E. (1949). Airplane performance stability and control. New York: John Wiley \& Sons.

Piper Aircraft Corporation. (1978). Seminole, PA-44-180, pilot's information manual. Vero Beach, FL: Piper Aircraft Corporation.

Piper Aircraft Corporation. (1988). Cadet, PA-28-161, information manual. Vero Beach, FL: Piper Aircraft Corporation.

Talay, T. A. (1975). Introduction to the aerodynamics of flight. NASA SP-367. Washington, D.C.:

National Aeronautics and Space Administration.

Van Sickle, N. D. (1987). Modern airmanship (rev. ed.). Blue Ridge Summit, PA: Tab Books. 